\title{
Disentangling Mechanisms in Natural Toxin Sorption to Soil Organic Carbon
}

\section{Journal Article}

\section{Author(s):}

Schönsee, Carina D.; Wettstein, Felix E.; Bucheli, Thomas D.

Publication date:

2021-04-20

\section{Permanent link:}

https://doi.org/10.3929/ethz-b-000487418

\section{Rights / license:}

Creative Commons Attribution-NonCommercial-NoDerivatives 4.0 International

\section{Originally published in:}

Environmental Science \& Technology 55(8), https://doi.org/10.1021/acs.est.0c06634 


\title{
Disentangling Mechanisms in Natural Toxin Sorption to Soil Organic Carbon
}

\author{
Carina D. Schönsee, Felix E. Wettstein, and Thomas D. Bucheli* \\ Cite This: Environ. Sci. Technol. 2021, 55, 4762-4771 \\ Read Online
}

ACCESS |

Llll Metrics \& More

Article Recommendations

Supporting Information

\begin{abstract}
Natural toxins are multifunctional, often ionizable organic compounds increasingly detected in the environment. Surprisingly little is known about their interactions with soil organic carbon, although sorption largely controls transport, bioavailability, and dissipation. For a set of 117 natural toxins from 36 compound classes the $\mathrm{pH}$-dependent organic carbonwater distribution coefficient $\left(D_{\text {oc }}\right)$ was quantified using a soil column chromatography approach under changing conditions with regards to $\mathrm{pH}$, ionic strength, and the major inorganic cation in solution. Natural toxins could be assigned to groups with either hydrophobic partitioning or specific interactions (complexation reactions, cation exchange) as dominating sorption mechanisms. The complex interplay of interactions in the sorption of natural

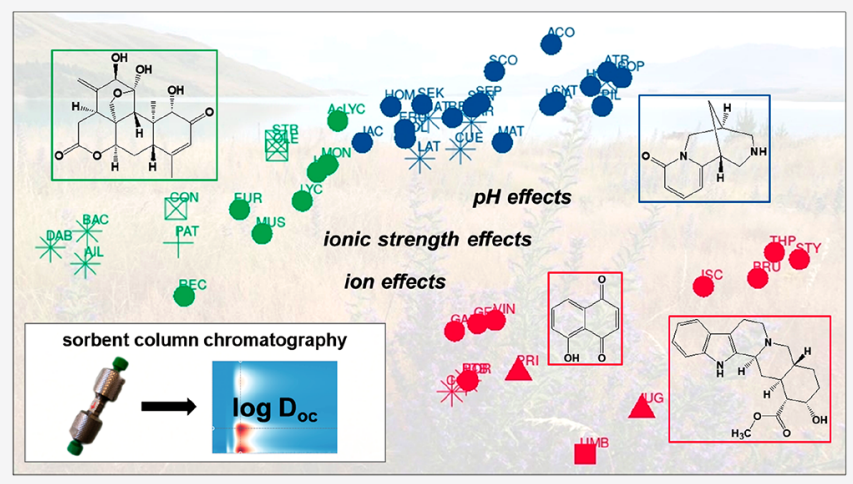
toxins was equally influenced by sorbate, sorbent, and solution specific characteristics. High variability in sorption was particularly observed in the presence of $\mathrm{Ca}^{2+}$ resulting in $D_{\mathrm{oc}}$ being enhanced by a factor of 10 when the $\mathrm{pH}$ was increased from 4.5 to 6 . Sorbates following this trend contain either functional groups able to form ternary complexes via $\mathrm{Ca}^{2+}$ or aromatic moieties adjacent to protonated $\mathrm{N}$ presumably stabilizing cation exchange reactions. Although sorption was often stronger than predicted, investigated natural toxins were highly mobile under all considered conditions.
\end{abstract}

KEYWORDS: environmental distribution, phytotoxins, mycotoxins, micropollutants, ionizable chemicals

\section{INTRODUCTION}

Natural toxins are a highly diverse group of biologically active, polar, multifunctional, and often ionizable compounds produced by, for example, plants (phytotoxins). ${ }^{1,2}$ While generally understudied in terms of their environmental occurrence, $^{3}$ some exemplary phytotoxin classes have been detected both in the soil and aquatic environment. For instance, concentrations of pyrrolizidine alkaloids (PA) can reach up to more than $1000 \mu \mathrm{g} / \mathrm{kg}$ in soils ${ }^{4}$ and vary from a few ng/L to several hundred $\mu \mathrm{g} / \mathrm{L}$ in surface waters. ${ }^{4,5}$ It is still not always fully understood how phytotoxins reach environmental compartments, but compounds can leach from decomposing plant material, ${ }^{6}$ be actively exudated via roots, ${ }^{7}$ or washed off the plants by rainfall. ${ }^{8}$ Once in the environment, the overall fate of phytotoxins is highly dependent on their properties. Toxic $(\mathrm{T})$ compounds that are persistent $(\mathrm{P})$ toward abiotic and biotic degradation can potentially be transported to drainage and surface waters or reach groundwater if they are mobile (M). Those so-called PMT compounds can contaminate potential drinking water abstraction sites or harm aquatic organisms by adding to the complex mixture of micropollutants. ${ }^{9,10} \mathrm{Up}$ until now, no commonly established quantitative descriptor for a compound's environmental mobility is defined. The organic carbon-water partition coefficient $\left(K_{\mathrm{oc}}\right)$ or, in the case of ionizable compounds the $\mathrm{pH}$-dependent organic carbon-water distribution coefficient $\left(D_{\text {oc }}\right)$, was recently recommended as primary criterion to assess mobility in the aquatic environment. ${ }^{9}$ The cutoff for a mobile compound was set to $\log K_{\mathrm{oc}}$ or $D_{\text {oc }}<4 .{ }^{10}$ In contrast to the octanol-water partition coefficient $\left(K_{\mathrm{ow}}\right)$, an acceptable indicator for the sorption tendency of neutral compounds dominated by hydrophobic partitioning, $K_{\mathrm{oc}}$ or $D_{\mathrm{oc}}$ additionally considers ion exchange and reversible reactions (e.g., surface complexation) occurring at specific charged sorption sites. ${ }^{9,11}$ Those interactions are not only dependent on the sorbate's properties (e.g., presence of complexing ligand functional groups) but are also strongly influenced by the sorbent characteristics and environmental conditions such as $\mathrm{pH}$ or solution composition. No reliable descriptive sorption models are currently available for multifunctional, ionizable compounds such as natural

Received: October 2, 2020

Revised: January 29, 2021

Accepted: March 11, 2021

Published: March 23, 2021 
toxins. $^{11,12}$ Thus, $K_{\mathrm{oc}}$ or $D_{\mathrm{oc}}$ for those structurally complex molecules still needs to be determined experimentally.

The quantification of sorption coefficients for large sets of compounds under various experimental conditions in traditional batch sorption experiments ${ }^{13}$ is highly material- and time-consuming and thus, not practicable. Therefore, flowthrough column experiments have been used for several years as an elegant alternative. Sorption coefficients are determined by assessing the retention of sorbates on a chromatographic column packed with the sorbent of interest. This approach has successfully been applied for both neutral as well as ionic organic and inorganic sorbates on various individual sorbents and soils. ${ }^{12,14-20}$ As demonstrated, column experiments are particularly valuable for the analysis of weakly sorbing or highly soluble compounds. For these, high solid-to-aqueous-phase ratios and thus large amounts of sorbent would be required in sorption batch experiments. Additionally, the investigation of environmental influences on sorption behavior is rather efficient in a column setup, by adjusting eluent composition to account for variations in $\mathrm{pH}$, ionic strength (IS), or counterions present in solution.

Overall, the major goals of this study were to (1) systematically investigate sorption of 117 natural toxins to soil organic carbon (SOC) using column chromatography as a high-throughput alternative to batch sorption experiments, (2) identify predominating sorption mechanisms of natural toxins by investigating the effect of changing $\mathrm{pH}$, IS, and counterions in solution, and (3) assess the mobility of natural toxins in comparison with commonly detected micropollutants found in groundwater or drinking water. Experimental sorption data for natural toxins has only been systematically determined for environmentally relevant mycotoxins, ${ }^{12}$ and is not yet available to any larger extent for phytotoxins. Thus, we provide the first holistic and extensive quantitative description of phytotoxin mobility $\left(D_{\text {oc }}\right)$ to assist exposure assessment and allow for reliable prioritization of those compound classes of potential relevance for water quality. Serving as model compounds for multifunctional, ionizable compounds in general, sorption data for natural toxins can also serve as a basis for future validation or development of robust predictive sorption models.

\section{MATERIALS AND METHODS}

2.1. Materials. A set of 117 natural toxins from 36 compound classes comprising 109 phytotoxins and eight mycotoxins was investigated in this study. The chosen sorbates covered a molecular weight range of $100-850 \mathrm{~g} / \mathrm{mol}$ and contained representatives of neutral, acidic, and basic ionizable compounds with varying functionalities. All natural toxin stock solutions and a solution of sodium nitrate $\left(\mathrm{NaNO}_{3}\right.$, SigmaAldrich, Buchs, Switzerland) as conservative tracer were prepared in methanol (HPLC grade, Sigma-Aldrich) and stored at $-20{ }^{\circ} \mathrm{C}$. Detailed information on selected compounds, supplier, and purity is given in Table S1 of the Supporting Information (SI). For molecular structures of all sorbates, refer to Tables S2-S6. Additional chemicals used were hydrochloric acid (37\%) as well as calcium chloride and sodium chloride (all Sigma-Aldrich). Aqueous eluents were prepared in ultrapure water (Milli-Q system, Merck Millipore, Darmstadt, Germany), and specific amounts of the salts and acid were added to establish the desired $\mathrm{pH}$ and IS (see below). Individual dilutions of each natural toxin and the conservative tracer were prepared in the respective eluent used for measurements while always assuring that the methanol concentration remained below $2 \%(\mathrm{v} / \mathrm{v})$.

Pahokee Peat soil (PP, 2BS103P, International Humic Substances Society IHSS, Golden, CO, USA) was used as reference organic sorbent, and silicon carbide ( $\mathrm{SiC}, \mathrm{ESK}-\mathrm{SiC}$, Frechen, Germany) was used as quasi-inert stationary phase material for dilution of the sorbent. Silicon carbide was used as received (particle size $10.8-13.3 \mu \mathrm{m}$ ), whereas PP was milled by pestle and mortar followed by sieving (stainless steel sieves ISO 3310-1, RETSCH, Haan, Germany) to get a defined particle range of $25-32 \mu \mathrm{m}$. General properties of the sorbent are given in Table 57.

Empty stainless steel HPLC columns (length $14 \mathrm{~mm}$; inner diameter $3 \mathrm{~mm}$ ) and additional equipment (precolumns, connecting nuts, stainless steel sieves of $3 \mu \mathrm{m}$ pore size, glass fiber filters of $<1.5 \mu \mathrm{m}$ pore size and PTFE sealing rings) were purchased from Bischoff Chromatography (distributed by WICOM International AG, Maienfeld, Switzerland).

2.2. Experimental Approach. Continuous flow column sorption experiments were performed on columns manually packed with the $\mathrm{SiC}$ supported sorbent to obtain $D_{\text {oc }}$ values under varying experimental conditions. The approach allows a direct derivation of the sorption coefficients from respective net retention times of the sorbates. Column packing procedures described in the literature for various pure sorbents $^{17,21}$ and reference soils ${ }^{21,22}$ were combined and optimized for this study. Details on the final method and characteristics of the prepared columns are given in section II of the SI. In short, PP was diluted with $\mathrm{SiC}$ by varying factors to generate columns with final PP contents of 1,5 , or $10 \%(w /$ w) and thus covering a broad range of sorption affinities. The mixture was dry-packed into the empty columns and compressed under increasing flow of an aqueous solution of $5 \mathrm{mM} \mathrm{CaCl}_{2}$ using an HPLC pump. In contrast to previous work using this approach, a precolumn filled with $\mathrm{SiC}$ only was used to have surplus quasi-inert stationary material to fill any potential voids occurring at the column head during compression. Further, columns packed with $\mathrm{SiC}$ were also prepared as reference columns. Eluents used in retention measurements were adjusted for $\mathrm{pH}$ (for details see below) but not actively buffered. However, eluents were always airequilibrated for at least $24 \mathrm{~h}$ to reach a stable $\mathrm{pH}$. Before measurements, each column was equilibrated for at least 8 h by flushing with the respective eluent at $0.1 \mathrm{~mL} / \mathrm{min}$. All retention measurements were finally performed using diode array detection at analyte-specific wavelengths (Table S10). The injection volume was set to $5 \mu \mathrm{L}$, the flow rate to $0.1 \mathrm{~mL} / \mathrm{min}$, and analysis temperature of the column oven to $25 \pm 1{ }^{\circ} \mathrm{C}$. A detailed description of the HPLC system used for column packing and retention measurements is given in Table S9.

Experimental conditions were varied with respect to $\mathrm{pH}(\mathrm{pH}$ 3, 3.08 \pm 0.08; $\mathrm{pH} 4.5,4.56 \pm 0.05$; and $\mathrm{pH} 6,5.96 \pm 0.1)$, IS ( $1 \mathrm{mM}, 15 \mathrm{mM}, 100 \mathrm{mM}$ ), and major cation type in solution $\left(\mathrm{Ca}^{2+}, \mathrm{Na}^{+}\right.$as $\mathrm{Cl}^{-}$salts). For each sorbate, $\log D_{\text {oc }}$ values were obtained at $\mathrm{pH} 4.5$ and $\mathrm{pH} 6$ in a solution of $5 \mathrm{mM} \mathrm{CaCl}_{2}$ (IS $15 \mathrm{mM})$ in line with similar sorption studies. ${ }^{12,21,23}$ Subsequently, sorbate subsets were investigated considering $\mathrm{pH}, \mathrm{IS}$, and ion effects on sorption.

2.3. Data Processing and Evaluation. Sorption coefficients were finally determined as described in a previous study (details in section III of the SI). ${ }^{12}$ Sorption coefficients $\left(D_{\mathrm{oc}}\right)$ of the sorbate normalized to the amount of organic carbon in the PP columns $\left(m_{\mathrm{oc}}\right)$ were determined as 


$$
D_{\mathrm{oc}}\left[\mathrm{L} \mathrm{kg}^{-1}\right]=\left(V_{\mathrm{R}, \mathrm{PP}}-V_{\mathrm{R}, \mathrm{SiC}}\right) / m_{\mathrm{oc}}
$$

with $V_{\mathrm{R}}$ being the retention volume obtained by multiplying the retention time of each individual sorbate with the constant flow rate of $0.1 \mathrm{~mL} / \mathrm{min}$ for the $\mathrm{PP}$ and $\mathrm{SiC}$ column, respectively. Final natural toxin $D_{\text {oc }}$ was calculated from a minimum of two injections passing the data validity criteria specified in the SI. All retention volumes were corrected for the dead volume of the setup and only those $30 \%$ larger than the retention volume of the tracer on the PP column were considered for further evaluation. This resulted in a lower limit of $\log D_{\text {oc }}=0.7$ for the PP columns. If the measured $\log D_{\text {oc }}$ was less than 0.7 , compounds were categorized as highly mobile and not further investigated with regards to their sorption mechanisms.

Retention times were determined based on the statistical first moment approach ${ }^{24}$ to account for peak asymmetry due to pronounced tailing. Four concentrations were injected for each sorbate to ensure sorption linearity in the considered concentration range $(0.01-0.78 \mathrm{mM}$, Table S11) and to derive standard deviations for $D_{\text {oc }}$ from replicate analysis. Fourpoint semiquantitative sorption isotherms were constructed analogous to similar previous studies ${ }^{12}$ for linearity testing.

As no experimental values were available for all natural toxins under investigation, $\mathrm{p} K_{\mathrm{a}}$ values were obtained from in silico predictions (ACD/Percepta, ${ }^{25}$ Chemicalize $^{26}$ ) to estimate each sorbate's ionization state under the given experimental conditions. Predicted $\log K_{\mathrm{oc}}$ values (EPISuite ${ }^{27}$ ) were used for comparison with experimentally derived data and experimental $\log K_{\mathrm{ow}}{ }^{28}$ gathered to describe compound polarity (Table S2-S6).

2.4. Quality Assurance and Control. Quasi-equilibrium conditions in columns were tested by applying different flow rates. Observed deviations in retention of weak to strong sorbing analytes resulted in a maximum $\log D_{\text {oc }}$ shift less than $0.1 \mathrm{log}$ unit when applying flow rates of 0.025 to $0.15 \mathrm{~mL} / \mathrm{min}$ and thus, were negligible (Figure S4). Comparing peak areas for the PP and $\mathrm{SiC}$ columns indicated that the mass balance of sorbates was complete (recovery $=92 \%$, average of 104 sorbates, Table S12). Interaction of the sorbates with $\mathrm{SiC}$ and the whole HPLC system was corrected for by measurements on the $\mathrm{SiC}$ column but was generally negligible. As expected for organic carbon as an amorphous sorbent, sorption was observed to be linear (linear fit $R^{2}=0.95-1.0$, data not shown) for all investigated natural toxins with maximum sorbed concentrations less than $1 \mathrm{mmol} / \mathrm{kg}_{\text {oc }}$ (Table S11).

Column packing was very stable as demonstrated by regular measurements of the conservative tracer $\mathrm{NaNO}_{3}$ and caffeine (CAF) as a retained quality control compound during sorption studies. No significant shift of either the dead time or the log $D_{\text {oc }}$ of CAF was observed for more than 800 injections over nine months under the same analysis conditions (Figures S5, S6). A comparison of obtained $\log D_{\mathrm{oc}}$ for various compounds on several individually packed columns with differing PP contents proved the excellent reproducibility between columns (Figure S7). Additionally, literature $\log D_{\text {oc }}$ values for previously investigated mycotoxins ${ }^{12}$ could be reproduced with a deviation of less than $0.1 \mathrm{log}$ units (Table S13). As deviations between data obtained on different columns with varying OC content did not show any significant differences, all data was finally pooled for $D_{\text {oc }}$ reporting and assessment of sorption mechanisms.

\section{RESULTS AND DISCUSSION}

3.1. Natural Toxin Sorption Behavior. On the basis of the established comprehensive data set (Tables S14-S20), sorbate, sorbent, and solution specific factors influencing the sorption of natural toxins to SOC and their relevant sorption mechanisms are discussed. Out of the total of 117 compounds analyzed, 44 were fully neutral under all investigated $\mathrm{pH}$, and 25 were fully charged (cationic), while 48 showed $\mathrm{pH}$ dependent ionization (partially cationic or anionic, partially neutral; Tables S2-S6). For polar compounds such as the selected natural toxins, affinity to SOC cannot be solely attributed to hydrophobic partitioning as generally assumed for nonpolar analytes. ${ }^{29}$ For multifunctional, ionizable compounds, interaction mechanisms can be further subdivided: first, interactions such as hydrophobic partitioning and electron donor-acceptor interactions (EDA) that can occur to some extent for all sorbates; second, ion exchange and reversible reactions such as complexation that can only occur for specific sorbates. The latter reactions can be substantially stronger and particularly drive the sorption of ionizable compounds. ${ }^{11}$

Furthermore, ion exchange and reversible reactions only occur on specific (charged) sorbent functional groups. Such groups include for example, carboxy-, phenoxy-, hydroxy-, or carbonyl-groups out of which particularly carboxy-groups on PP became increasingly deprotonated with increasing solution $\mathrm{pH} .{ }^{34}$ Specifically carboxylate groups are also able to complex metal cations (Table S7). ${ }^{35-37}$ Thus, the agglomeration of PP and accessibility of functional groups for specific interactions is influenced by both $\mathrm{pH}$ and IS of the solution. ${ }^{34}$ The PP used in this study is overall negatively charged under all experimental conditions though (point of zero charge $=1.5-2.0$ ), ${ }^{30}$ and shows a high polarity with an oxygen-to-carbon atomic ratio of $0.48^{30}$ and high aromaticity in comparison with other types of SOC. ${ }^{30-33}$ Nevertheless, a previous study found PP to be a good surrogate for representative soils, as the obtained experimental $K_{\mathrm{oc}}$ values were comparable for a set of 118 polar but nonionizable sorbates. ${ }^{21}$

On the basis of the experimental trends in sorption behavior, 92 natural toxins could be assigned to four major groups (Tables S2-S5): sorbates dominated by hydrophobic partitioning (group HYP), showing complexation reactions (group COP), driven by cation exchange (group CE), and those natural toxins showing cation exchange stabilized only at $\mathrm{pH} 6$ in the presence of $\mathrm{Ca}^{2+}$ (group CES). This grouping was further confirmed by cluster analysis for those sorbates for which data was quantified under all experimental conditions $(n$ $=49$, Figure S8). Differences within and among groups were evaluated by means of statistical $t$ tests. The groups can only be partially attributed to the compounds' ionization in the investigated $\mathrm{pH}$ range as will be discussed in more detail below. Eight out of the 92 natural toxins assigned to groups (benzopyrans, steroids, a flavone, a zwitterionic alkaloid; group $\mathrm{HYP} / \mathrm{REP}$ ) were mainly included in investigations of $\mathrm{pH}$ trends only and thus not further discussed as a distinctive fifth group. They all have major acidic functional groups (hydroxyor carboxy-groups) that became increasingly deprotonated with increasing $\mathrm{pH}$. A decrease in sorption affinity could for example be seen for the cardenolide oleandrine or the phenylpropanoid 2-hydroxycinnamic acid. For these sorbates sorption was increasingly influenced by repulsive forces between the negatively charged, deprotonated sorbate functional groups and analogous groups on PP. These interactions 

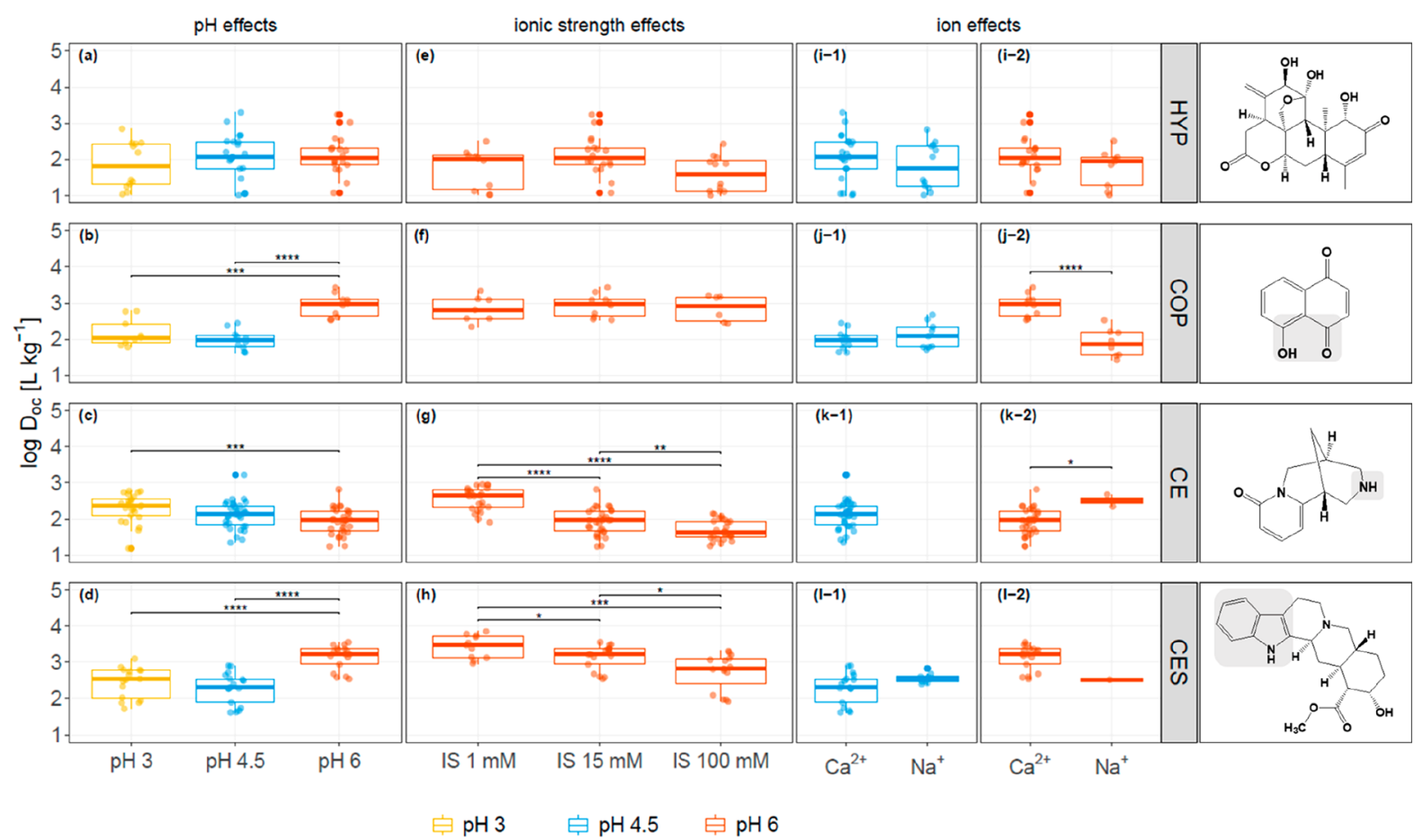

Figure 1. Experimentally determined $\log D_{\mathrm{oc}}$ of natural toxins in dependence of changing $\mathrm{pH}$ (panels a-d, IS $=15 \mathrm{mM} \mathrm{CaCl}$ ), ionic strength (panels $\mathrm{e}-\mathrm{h}, \mathrm{pH} \mathrm{6}, \mathrm{CaCl}_{2}$ ), and the major ion in solution (panels i-1 to 1-1: $\mathrm{pH} \mathrm{4.5,} \mathrm{i-2} \mathrm{to} \mathrm{1-2:} \mathrm{pH}$ 6, both IS = $15 \mathrm{mM}$ ) for each of the assigned compound groups (HYP $(n=23)$, panels a, e, i; COP $(n=10)$, panels b, f, j; CE $(n=33)$, panels c, g, k; CES $(n=18)$, panels d, h, l). Individual group names are derived by the main sorption mechanism: $\mathrm{HYP}=$ hydrophobic partitioning; $\mathrm{COP}=$ surface complexation; $\mathrm{CE}=$ cation exchange; CES $=$ stabilized cation exchange. The significance levels $(*, p \leq 0.05 ; * *, p \leq 0.01 ; * * *, p \leq 0.001 ; * * * *, p \leq 0.0001$, all others nonsignificant with $p>0.05)$ are the result of a $t$ test comparing respective means. Individual points on the boxplots represent measured log $D_{\text {oc }}$ Exemplary compounds for each class are depicted on the right (from top to bottom: ailanthone, juglone, cytisine, and yohimbine) with respective main structural features highlighted in gray.

were stronger than hydrophobic interactions dominating the sorption of the neutral species at low $\mathrm{pH}$, resulting in lower sorption affinities of the deprotonated sorbates. ${ }^{11}$ Another 25 natural toxins (Table S6) were not extensively evaluated with regards to their respective sorption mechanism as they were not investigated under all experimental conditions (limited amount of sorbates in stock at time of experiments) or their sorption was too weak $\left(\log D_{\text {oc }}<0.7\right)$ to obtain quantitative results.

3.1.1. Sorption of Neutral Natural Toxins. The first major group comprised 23 neutral analytes including terpenoids, coumarins, aldehydes, and ketones as well as nonionizable alkaloids (group HYP). The sorption affinity of the HYP compounds ranged between a $\log D_{\mathrm{oc}}<0.7$ to 3.3 and did not significantly change with increasing $\mathrm{pH}$ (Figure 1a). In the presented experimental range, no $\mathrm{pH}$ effects were expected to occur for nonionic sorbates independent of their polarity and thus potential for $\mathrm{H}^{+}$-donor-acceptor (HDA) interactions. Compounds assigned to the HYP group possess up to eight $\mathrm{H}^{+}$-donor groups and up to 14 acceptors. However, these polar groups may be inaccessible for those interactions due to the degree of molecular branching and steric hindrance. ${ }^{21,38}$ Neither changing IS (Figure 1e) nor the major ion in solution (Figure 1i) led to a significant alteration in sorption behavior. For the exemplary HYP terpenoid ailanthone (Figure 1) all changes in experimental conditions led to absolute $D_{\text {oc }}$ differences less than $0.1 \log$ units. This deviation was in the same range as the average maximum observed experimental errors. These results confirmed those of previous studies for nonionic compounds and O-heterocycles in particular, for which no specific interactions were detected. ${ }^{19}$ Thus, sorption was solely attributed to hydrophobic partitioning into SOC.

Another subgroup of 10 neutral analytes (group COP) including amides, benzoquinones, coumarins, lactones, and a terpenoid showed nonsignificant changes in sorption affinity with increasing IS (Figure 1f). However, this group exhibited a highly significant increase in sorption $(\sim 1 \log$ unit) at $\mathrm{pH} 6$ in the presence of the divalent $\mathrm{Ca}^{2+}$ in solution in comparison with the monovalent $\mathrm{Na}^{+}$(Figure 1j-2). Overall, $\log D_{\text {oc }}$ values for the COP group ranged between 1.4 and 3.4. One example for the natural toxins of this group is the benzoquinone juglone (JUG, Figure 1) which showed an increase in $\log D_{\mathrm{oc}}$ of $1.1 \log$ units when $\mathrm{pH}$ increased from 4.5 to 6 and a decrease of log $D_{\text {oc }}$ of $1.1 \log$ units when $\mathrm{Ca}^{2+}$ was replaced with $\mathrm{Na}^{+}$in solution.

With increasing negative charge of $\mathrm{PP}, \mathrm{Ca}^{2+}$ is more strongly associated with the peat and facilitates sorption of compounds such as JUG and the others in the COP group by potential ternary complex formation (coadsorption of the cation and organic molecule). ${ }^{39}$ The example JUG has a hydroxyl- and carbonyl-functional group one carbon apart particularly favoring complex formation. ${ }^{40}$ In general, this process is mainly known for mineral surfaces but was also suggested to occur in organic matter phases that contain cation exchange groups and complexed metals. ${ }^{35}$ The fact that no significant effects of increasing IS were observed (Figure 1f) can be attributed to $\mathrm{Ca}^{2+}$ being present in excess in comparison with the sorbate at any given IS. Strong sorption of structurally similar complexing compounds in the $\mathrm{pH}$ range between $\mathrm{pH}$ 5.5 and 6 was previously demonstrated for the antibiotics 
ciproflaxin and oxytetracycline for both soils and peat, ${ }^{31,35,41}$ and assigned to surface complexation. ${ }^{42}$ This effect is only significant with $\mathrm{Ca}^{2+}$ as $\mathrm{Na}^{+}$remains almost entirely in solution instead of complexing organic matter functional groups. ${ }^{37}$ This influence of divalent cations on sorption affinity has been shown in several previous studies. ${ }^{16,38}$ Natural toxins in the COP group additionally have up to seven HDA functional groups (narciclasine) and a maximum of three aromatic rings (isopimpinellin). Molecular dynamics relaxation studies highlighted the complementary effect of those functional groups with HDA capacity that may further stabilize ternary complexes. $^{42}$ Studies also suggested that large nonpolar moieties favor enhanced surface complexation due to pronounced exclusion of those sorbates from the aqueous phase. $^{40}$

3.1.2. Sorption of lonized Natural Toxins. The last two groups comprised $51 \mathrm{~N}$-containing, mainly cationic sorbates (base $\mathrm{pK}_{\mathrm{a}}$ 6-10) that could be subdivided into 33 largely saturated N-heterocyclic alkaloids (group CE, $1.2<\log D_{\mathrm{oc}}<$ 3.2) and $18 \mathrm{~N}$-heterocycles with aromatic functionalities (group CES, $1.6<\log D_{\text {oc }}<3.9$ ). This subdivision was made to differentiate variable trends in sorption affinities with changing $\mathrm{pH}$ and IS, as discussed in the following section. Electrostatic interactions were expected to dominate over weaker hydrophobic, HDA, or EDA interactions but do not exclude these interaction types. ${ }^{11}$ Particularly, sorption of $\mathrm{N}$ heterocycles was previously shown to be different compared to, for example, O-/S-heterocycles and majorly influenced by specific cation exchange interactions contributing to more than $70 \%$ of their overall sorption affinity. ${ }^{19,21,23}$

3.1.2.1. Cation Exchange Dominated Sorption of $N$ Heterocycles. For the largely cationic N-heterocyclic alkaloid natural toxins (group $\mathrm{CE}$ ), it was expected that cation exchange interactions would clearly drive their sorption behavior. However, the overall trend over the investigated $\mathrm{pH}$ range was counterintuitive as sorption of the cationic form decreased on average $0.3 \log$ units with increasing $\mathrm{pH}$ from 3 to 6 although the sorbent became more and more negatively charged (Figure 1c). A similar trend has been described for positively charged amines that showed on average 0.2 log units higher sorption affinities at $\mathrm{pH} 4.5$ in comparison to $6.8 .^{38}$ To a small extent the decrease observed for natural toxins may be attributed to 12 analytes with a predicted base $\mathrm{p} K_{\mathrm{a}}$ in the range of 2.4-6.0 becoming at least partially neutral with increasing $\mathrm{pH}$ (nucleosides and purines, e.g., cordycepin). Those compounds lose their ability to undergo attractive electrostatic interactions. Hydrophobic interactions, generally weaker, become dominant for increasingly neutral compounds but may be less prominent as the sorbent becomes less hydrophobic due to increased deprotonation of its functional groups. However, removing those natural toxins from the $\mathrm{CE}$ group did not lead to a significant change in the overall decrease of sorption affinities with increasing $\mathrm{pH}$. Please note that the compounds' predicted $\mathrm{p} K_{\mathrm{a}}$ are rather uncertain though as previously observed in a study on natural toxins' $\mathrm{pH}$ dependent $K_{\mathrm{ow}}{ }^{28}$

Apart from that, aqueous chemistry and particularly the presence of polyvalent cations such as $\mathrm{Ca}^{2+}$ can also change the conformation of humic materials by cross-linking. This affects sorption by enhancing structural agglomeration, thus limiting the accessibility of charged functional groups and simultaneously favoring nonspecific interactions. ${ }^{36}$ The effect is generally expected to be rather small though $(<0.2$ log units), ${ }^{40}$ but was in close agreement with the presented average decrease observed for a $\mathrm{pH}$ rise from 3 to 6 (Figure 1c). Therefore, the higher affinity of cationic N-heterocycles to SOC at lower $\mathrm{pH}$ may partially be caused by $\mathrm{Ca}^{2+}$ affecting rather the sorbent than the sorbates. ${ }^{38}$

The importance of electrostatic interactions driving cationic $\mathrm{N}$-heterocycle sorption was demonstrated by highly significant effects of increasing IS in solution (Figure 1g). An IS increase by a factor of 100 led to an average decrease in sorption affinity of about one log unit. With increasing IS the number of $\mathrm{Ca}^{2+}$ competing for deprotonated sorbent functional groups is enhanced and the inorganic cation out-competes the large organic cation. The effect was highly significant when changing from a very low IS of $1 \mathrm{mM}$ to $15 \mathrm{mM}$ and slightly less pronounced when increasing IS further to $100 \mathrm{mM}$. Additionally, with $\mathrm{Na}^{+}$as a weaker competitor in solution in comparison to $\mathrm{Ca}^{2+}$, the average $\log D_{\text {oc }}$ of the CE group at $\mathrm{pH} 6$ was increased by about $0.5 \log$ units (Figure $1 \mathrm{k}$ ). This particular competitive effect was previously described for cationic $\mathrm{N}$-heterocycles in the presence of either the monovalent $\mathrm{K}^{+}$or divalent $\mathrm{Ca}^{2+19}$ and confirmed cation exchange as the major sorption mechanism for the CE group.

3.1.2.2. Sorption of $\mathrm{N}$-Heterocycles by Complementary Mechanisms to Cation Exchange. The second group of largely cationic N-heterocycles (group CES) also exhibited strong indications for cation exchange as the major sorption mechanism. In contrast to the previously described CE group though, the CES sorbates did show a highly significant increase in sorption affinity when the $\mathrm{pH}$ increased from 4.5 to 6 (Figure $1 \mathrm{~d}$ ). The $D_{\text {oc }}$ of the indole alkaloid yohimbine (Figure 1 ) as an exemplary compound of the CES group was almost a factor of 10 larger at $\mathrm{pH} 6$ than at $\mathrm{pH} 4.5$. Ionic strength effects were, although significant, on average slightly less pronounced than for the CE group ( 0.7 log units, Figure $1 \mathrm{~h})$.

These differences between the CE and CES group must be attributed to the compounds' molecular structures. For example benzotriazoles, $\mathrm{N}$-heterocycles that display similar functionalities to the alkaloids investigated here, also demonstrated enhanced sorption under the same experimental conditions $\left(\mathrm{pH} 6, \mathrm{Ca}^{2+}\right)$. Analogous to the potentially favored complexation of neutral natural toxins with large apolar moieties due to their stronger exclusion from the aqueous phase, hydrophobic exclusion may play a role in favoring sorption of $\mathrm{N}$-heterocycles with aromatic moieties as well. Additionally, polyaromatic molecules, particularly those with protonated $\mathrm{N}$ moieties, displayed enhanced sorption. ${ }^{38}$ Those types of compounds are strong $\pi$-acceptors, particularly in their cationic form or with additional carbonyl- or carboxylicfunctional groups. The $\pi$-acceptor capability may allow them to form $\pi-\pi$ complexes with both $\pi$-acceptor and predominantly -donor groups of SOC, interactions that are of notable strength and generally known from, for example, DNA base stacking. ${ }^{43}$ The formation of cation $-\pi$-complexes is possible for interactions of the protonated form of the $\mathrm{N}$-heterocycles with SOC. In this case, aromatic binding is particularly enhanced by the electron deficiency of the sorbate and the corresponding excess of electrons of the sorbent. Complex formation reactions involving $\pi$-interactions are electrostatic interactions that can become dominant in the, in comparison with water, rather nonpolar environment of SOC. ${ }^{44}$ Soil organic carbon has several moieties with a strong $\pi$-acceptor property that are not $\mathrm{pH}$-dependent (e.g., quinone), and those moieties are excellent for cation $-\pi$-complex formation. ${ }^{44,45}$ 


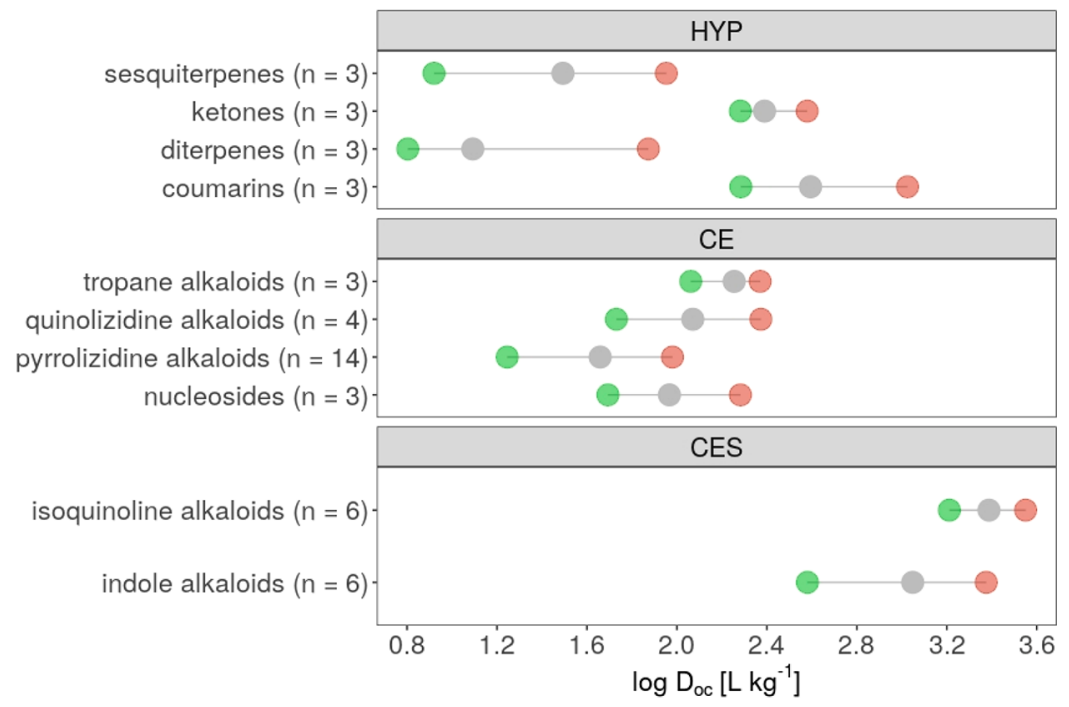

Figure 2. Range of experimentally determined $\log D_{\text {oc }}$ of different natural toxins subclasses with $n \geq 3$ representing three out of the four major groups. Presented are $\log D_{\mathrm{oc}}$ values at $\mathrm{pH} 6$ in a $\mathrm{CaCl}_{2}$ solution of IS $15 \mathrm{mM}$; green dot $=$ minimum $\log D_{\text {oc }}$ gray dot $=$ geometric mean $\log D_{\text {oc }}$ red dot $=$ maximum $\log D_{\mathrm{oc}}$. Individual group names are derived by the main sorption mechanism: HYP = hydrophobic partitioning; CE = cation exchange; CES = stabilized cation exchange.

These specific interactions involving the aromatic moieties explain why compounds in the CES group sorbed on average more than one log unit stronger than those in the CE group at pH 6 (Figure 1c,d). This higher extent of aromatic Nheterocycle sorption was also previously demonstrated for clay surfaces and was additionally attributed to the enhanced electrostatic overlap of the positive charge delocalized within the electron-deficient ring of the sorbate and electron-rich moieties of the sorbent surface. Because of the enhanced overlap, the sorption of planar compounds such as polyaromatics as the investigated isoquinoline alkaloids (e.g., papaverine) is generally more favorable. ${ }^{46}$ Charge delocalization is not possible for the few exceptions of the CE group that contain aromatic moieties as for instance the tropane alkaloid atropine or the quinolizidine alkaloid cytisine. They either do not contain unsaturated moieties in proximity to the protonated $\mathrm{N}$ available for charge delocalization or are generally molecules with a comparably nonplanar (bulky) molecular conformation.

Moreover, the significantly increased sorption affinity of the CES group sorbates only observed at $\mathrm{pH} 6$ seems again a result of the previously discussed effect of divalent cations such as $\mathrm{Ca}^{2+}$ on sorption by triggering ternary complex formation. ${ }^{19}$ For the literature example of indole, enhanced interactions were also demonstrated between cations and the $\pi$-electron systems of the $\mathrm{N}$-heterocycle in comparison with aromatic hydrocarbons, ${ }^{47}$ thus stressing the potential of N-heterocycles to form ternary complexes. Those complexes may be further stabilized, even to some extent enhanced, by the described cation $-\pi-, \pi-\pi$-, and HDA-interactions. Further, they are generally most prominent at $\mathrm{pH} 6$ at which $\mathrm{Ca}^{2+}$ shows its strongest association with $\mathrm{SOC}$ in the investigated $\mathrm{pH}$ range due to smaller competition with $\mathrm{H}^{+}$for deprotonated sorbent functional groups. ${ }^{31,42,45}$

Considering that most alkaloids in the CES group are either indole or quinoline/isoquinoline alkaloids, which are derivatives of the above-described types of N-heterocyclic compounds, similar mechanisms may occur in the sorption of phytotoxins to specific SOC moieties as well. Additionally, the fact that CES compounds showed less pronounced effects by competition with $\mathrm{Ca}^{2+}$ (Figure $1 \mathrm{~h}$ ), was potentially due to the IS effect being hampered by those additional specific HDA and EDA interactions. Overall, sorption of compounds in the CES group was primarily the result of an interplay of various electrostatic interactions involving cation exchange as well as aromatic interactions and complexation reactions.

3.1.3. Compound Class Dependent Sorption. The average $\log D_{\text {oc }}$ of natural toxin compound classes with a minimum of three analyzed individual compounds was compared based on their respective geometric means (representing the central tendency of unevenly distributed data sets). While compound classes dominated by hydrophobic partitioning (group HYP) showed a variable geometric mean of minimum $\log D_{\mathrm{oc}}=1.1$ for diterpenes to a maximum $\log D_{\mathrm{oc}}=2.6$ for coumarins, natural toxins of the groups dominated by a more specific sorption mechanism (groups CE, CES) exhibited relatively close agreement of geometric means (within 0.6 log units, Figure 2). No such evaluation could be done for the COP group due to the high diversity of compound classes and limited number of individuals per class within the group.

This general observation, although based on a limited number of compounds, indicates that the geometric means of $\log D_{\mathrm{oc}}$ for groups of ionizable compounds containing the same major functional moieties could be useful for preliminary mobility assessment. Obtained data for PA, the most mobile alkaloid class for which 26 different compounds were investigated at $\mathrm{pH} \mathrm{6,} \mathrm{allowed} \mathrm{a} \mathrm{description} \mathrm{of} \mathrm{this} \mathrm{trend} \mathrm{in}$ more detail. Out of the $26 \mathrm{PA}$ the $12 \mathrm{PA} \mathrm{N}$-oxides exhibited a $\log D_{\mathrm{oc}}$ less than 0.7 and were not quantifiable. Thus, excluding the $\mathrm{N}$-oxides, the PA showed a geometric mean of $\log D_{\mathrm{oc}}=$ $1.65(n=14)$. Their sorption affinity ranged from a minimum of $\log D_{\text {oc }}=1.25$ to a maximum of 1.98 (Table S16) although PA show variable structures (Figure S4) with between one and three $\mathrm{H}^{+}$-bond donor functional groups (e.g., hydroxy-groups) or four to six $\mathrm{H}^{+}$-bond acceptors (e.g., carbonyl-groups). The majority of the PA investigated are fully cationic and based on the same core structure, the retronecine subunit, which alone had a $\log D_{\text {oc }}$ of 1.26 . Thus, adding to this core structure 


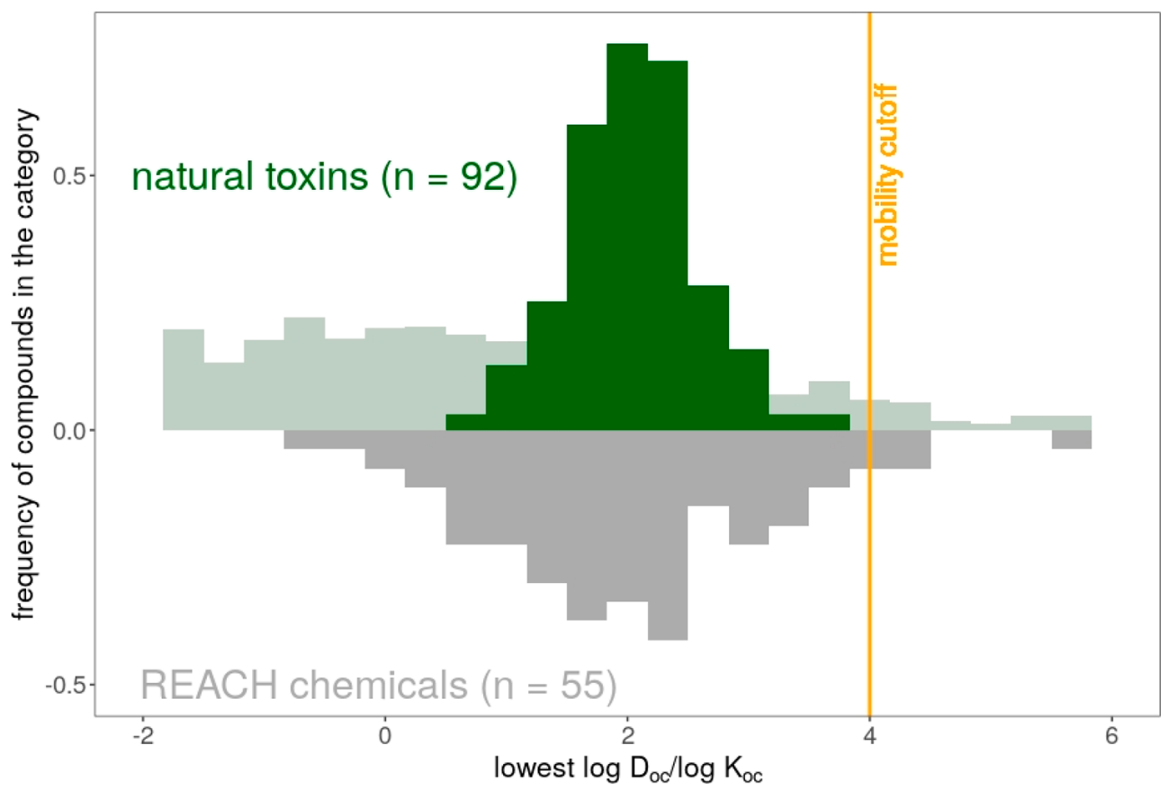

Figure 3. Comparison of the mobility of natural toxins (green, top) and REACH registered chemicals (gray, bottom) as defined by the lowest experimental $\log K_{\mathrm{oc}}$ or $D_{\mathrm{oc}}$ in the $\mathrm{pH}$ range 4-9. For comparison, the lowest predicted $\log K_{\mathrm{oc}}$ or $D_{\mathrm{oc}}$ for those phytotoxins (light green, top) with a $\log K_{\mathrm{oc}}$ or $D_{\mathrm{oc}}$ between -2 and 6 are shown as presented in the phytotoxin database by Günthardt et al.; ${ }^{2}$ predicted $\log K_{\mathrm{oc}}$ or $D_{\mathrm{oc}}$ in the database actually range from -27 to 6.5 with only $4.2 \%$ of phytotoxins above the mobility cutoff of 4 . Data for REACH chemicals was adapted from the report by Neumann and Schliebner. ${ }^{10}$

increased the $\log D_{\text {oc }}$ by less than one $\log$ unit. In more detail, PA open-chain monoesters had an average $\log D_{\text {oc }}$ of $1.43(n=$ $4)$, open chain diesters of $1.92(n=2)$ and cyclic diesters of $1.86(n=5)$. On this basis, it could be hypothesized that the major functional moieties that define a compound class dominate its overall sorption behavior.

The overall trend with consistent variations of sorption affinities of cationic compounds with similar structure was additionally in close agreement with previous studies estimating structural scaling factors for modeling organic cation sorption. ${ }^{48}$ Combining such factors with results for the sorption affinity of a simple probe cation allowed for estimation of sorption affinities for structurally more complex organic cations with relatively low mean absolute errors, particularly when including competitive effects by inorganic cations. ${ }^{49}$ The consistent trends for the four groups of natural toxins (Figure 1) and the on-average highly similar sorption affinities of compounds with the same core structure (Figure 2) as specifically demonstrated for the PA subclass above, additionally prove the probe compound concept introduced by Jolin et al. $^{49}$ to be a promising step forward in predicting multifunctional, ionizable sorption.

3.2. General Implications from Natural Toxin Sorption Behavior. Natural toxin sorption behavior evaluated under changing solution properties demonstrated that sorption affinities for multifunctional, particularly ionizable, organic compounds are the result of a complex interplay of different sorption mechanisms. Those are highly dependent not only on the compound's characteristics such as functionality or ionizability, but also the position of functional groups or moieties within the molecule. The latter is specifically important for complexation reactions as described for the COP and CES group of natural toxins. Additionally, the sorbent properties such as functionality, aromaticity, and complexing potential for metal cations directly influence sorption behavior of organic molecules. All in all, this interplay stresses once more why it is still not possible to predict sorption behavior of a large number of ionizable compounds to a satisfactory degree. ${ }^{11}$ However, we could further manifest that models based on experimental data for probe compounds containing frequently detected core structures may show promise for future development of robust predictive models. ${ }^{49}$

Thus, prospective experimental investigations should always include $\mathrm{pH}$ - and IS-dependent evaluation, particularly when $\mathrm{N}$ heterocyclic sorption behavior is involved. Complex stability constants for those compounds would also be a great advancement in understanding their sorption behavior. Particularly the role of HDA as well as EDA interactions in stabilization of those complexes should be further elucidated. The results for the alkaloid class of natural toxins is one example specifically stressing this need. In this study, investigated alkaloids were predominantly fully cationic under experimental conditions; however, general conclusions could not be drawn for alkaloids as a whole group as demonstrated by the differences observed for the CE and CES group alkaloids. While sorption of one group was simply dominated by cation exchange, the other group showed strong influences by additional interactions as well. As N-heterocyclic structures are often present in commonly used pesticides or pharmaceuticals, mechanistic understanding of their sorption behavior and thus environmental mobility is of increasing importance. Therefore, the generation of more sorption data of multifunctional, ionizable compounds under changing experimental conditions is highly relevant. The data on natural toxin sorption presented here can be used as a starting set for the development of new, more robust structure-based sorption models by, for example, multiple regression analysis. These can then be used in environmental risk assessment by predicting the mobility of other polar and ionizable compounds with related structure.

3.3. Environmental Mobility of Natural Toxins. Experimentally determined natural toxin $\log D_{\text {oc }}$ values show 
that chosen representatives of the three major compound classes, terpenoids, isoprenoids, and alkaloids, are rather mobile. Additionally, certain subclasses need to be categorized as highly mobile according to the recently proposed limits for mobility. ${ }^{10}$ On the basis of obtained $\log D_{\text {oc }}$ values at conditions closest to those in the natural environment $(\mathrm{pH}$ $6, \mathrm{CaCl}_{2}$ solution, IS $15 \mathrm{mM}$ ), $84 \%$ of all investigated natural toxins have to be classified as very mobile compounds with a $\log D_{\text {oc }}$ less than 3 (Table S16). A preliminary mobility assessment for plant toxins performed with in silico predicted data categorized $90 \%$ out of a total of 1506 representative compounds as highly mobile. ${ }^{2}$ Although experimentally derived values deviate significantly from predicted values given in said database (Figure S9), the high mobility of plant toxins is generally confirmed. The largest deviations can be seen for $\mathrm{N}$-containing natural toxins which are largely predicted to not have any preference toward either organic carbon or water.

Overall, mobility was suggested to be the result of the plant toxins' high polarity as indicated by generally low $\mathrm{K}_{\mathrm{ow}}$ as well as the small percentage of truly neutral compounds (39\%) in the database. ${ }^{2}$ These observations also hold true for the chosen compound set with experimental $\log \mathrm{K}_{\mathrm{ow}}$ ranging from -1.3 to 2.7 (Table S2-6) ${ }^{28}$ and a similar percentage of neutral compounds (38\%).

A comparison of compound mobility based on the lowest observed $\log K_{\mathrm{oc}}$ or $D_{\mathrm{oc}}$ in the $\mathrm{pH}$ range 4-9 as suggested for exposure assessment ${ }^{10}$ shows that natural toxins are highly similar to anthropogenic chemicals that passed the so-called $\mathrm{REACH}$ regulation for registration of chemicals in the European Union (Figure 3). The proposed limits used in the mobility ranking were derived based on the $\log K_{\mathrm{oc}}$ or $D_{\mathrm{oc}}$ of those REACH chemicals found in either ground- or drinking water. ${ }^{10}$ Thus, it is likely that those very mobile natural toxins may surpass environmental barriers such as soils and enter surface water and potentially even groundwater as well. This has been proven by recent studies reporting the presence of exemplary mobile natural toxins such as the mycotoxins nivalenol and deoxynivalenol, ${ }^{50}$ various isoflavones, ${ }^{5,51}$ the norsesquiterpene glucoside ptaquiloside, ${ }^{52}$ the indole alkaloid gramine, ${ }^{5}$ or $\mathrm{PA}^{4,5}$ in water resources.

\section{ASSOCIATED CONTENT}

\section{SI Supporting Information}

The Supporting Information is available free of charge at https://pubs.acs.org/doi/10.1021/acs.est.0c06634.

Details on natural toxin characteristics including molecular structures and physicochemical property data; description of column packing materials, packing method, data evaluation as well as quality assurance and control experiments; experimentally obtained $\log D_{\text {oc }}$ data for single compounds; additional result graphics depicting grouping and observed trends (PDF)

\section{AUTHOR INFORMATION}

\section{Corresponding Author}

Thomas D. Bucheli - Environmental Analytics, Agroscope, 8046 Zürich, Switzerland; 이이.org/0000-0001-99713104; Phone: 00415846873 42;

Email: thomas.bucheli@agroscope.admin.ch

\section{Authors}

Carina D. Schönsee - Environmental Analytics, Agroscope, 8046 Zürich, Switzerland; Institute of Biogeochemistry and Pollutant Dynamics, ETH Zürich, 8092 Zürich, Switzerland

Felix E. Wettstein - Environmental Analytics, Agroscope, 8046 Zürich, Switzerland

Complete contact information is available at:

https://pubs.acs.org/10.1021/acs.est.0c06634

\section{Notes}

The authors declare no competing financial interest.

\section{ACKNOWLEDGMENTS}

This project received funding from the European Union's Horizon 2020 research and innovation program under the Marie Sklodowska-Curie Grant Agreement No. 722493 (NaToxAq). The authors would like to specifically thank Inge Stockinger (Agroscope), Johanna Keita (Agroscope), Urs Lustenberger (ETH Zürich), Iso Christl (ETH Zürich), Steven Droge (University of Amsterdam), Florian Metzelder, and Inés Rodríguez Leal (Stockholm University) for assistance during setup, execution, and evaluation of the experiments. ESK-SiC (Frechen, Germany) is acknowledged for donating silicon carbide, and Mulatu Nanusha (UFZ Leipzig), Werner Brack (UFZ Leipzig), and Barbara Günthardt (Agroscope) are acknowledged for providing additional reference standards. Furthermore, the authors would like to show their appreciation for the continuous support by Kristopher McNeill (ETH Zürich).

\section{REFERENCES}

(1) Teuscher, E.; Lindequist, U. Biogene Gifte, 3rd ed.; Wissenschaftliche Verlagsgesellschaft: Stuttgart, Germany, 2010.

(2) Günthardt, B. F.; Hollender, J.; Hungerbühler, K.; Scheringer, M.; Bucheli, T. D. Comprehensive Toxic Plants-Phytotoxins Database and Its Application in Assessing Aquatic Micropollution Potential. J. Agric. Food Chem. 2018, 66, 7577-7588.

(3) Bucheli, T. D. Phytotoxins: environmental micropollutants of concern? Environ. Sci. Technol. 2014, 48, 13027-13033.

(4) Hama, J. R.; Strobel, B. W. Pyrrolizidine alkaloids quantified in soil and water using UPLC-MS/MS. RSC Adv. 2019, 9, 3035030357.

(5) Günthardt, B. F.; Schönsee, C. D.; Hollender, J.; Hungerbühler, K.; Scheringer, M.; Bucheli, T. D. "Is there anybody else out there?" First Insights from a Suspect Screening for Phytotoxins in Surface Water. Chimia 2020, 74, 129-135.

(6) Nowak, M.; Wittke, C.; Lederer, I.; Klier, B.; Kleinwachter, M.; Selmar, D. Interspecific transfer of pyrrolizidine alkaloids: An unconsidered source of contaminations of phytopharmaceuticals and plant derived commodities. Food Chem. 2016, 213, 163-168.

(7) Selmar, D.; Wittke, C.; Beck-Von Wolffersdorff, I.; Klier, B.; Lewerenz, L.; Kleinwachter, M.; Nowak, M. Transfer of pyrrolizidine alkaloids between living plants: A disregarded source of contaminations. Environ. Pollut. 2019, 248, 456-461.

(8) Rasmussen, L. H.; Jensen, L. S.; Hansen, H. C. B. Distribution of the Carcinogenic Terpene Ptaquiloside in Bracken Fronds, Rhizomes (Pteridium aquilinum), and Litter in Denmark. J. Chem. Ecol. 2003, 29, 771-778.

(9) Reemtsma, T.; Berger, U.; Arp, H. P.; Gallard, H.; Knepper, T. P.; Neumann, M.; Quintana, J. B.; Voogt, P. Mind the Gap: Persistent and Mobile Organic Compounds-Water Contaminants That Slip Through. Environ. Sci. Technol. 2016, 50, 10308-10315.

(10) Neumann, M.; Schliebner, I. Protecting the sources of our drinking water: The criteria for identifying persistent, mobile and toxic $(P M T)$ substances and very persistent and very mobile ( $v$ PvM) substances 
under EU Regulation REACH (EC) No 1907/2006; German Environment Agency: Dessau-Roßlau, Germany, 2019; p 87.

(11) MacKay, A. A.; Vasudevan, D. Polyfunctional ionogenic compound sorption: challenges and new approaches to advance predictive models. Environ. Sci. Technol. 2012, 46, 9209-9223.

(12) Schenzel, J.; Goss, K. U.; Schwarzenbach, R. P.; Bucheli, T. D.; Droge, S. T. Experimentally determined soil organic matter-water sorption coefficients for different classes of natural toxins and comparison with estimated numbers. Environ. Sci. Technol. 2012, 46, $6118-6126$.

(13) OECD 106: Adsorption-Desorption Using a Batch Equilibrium Method. OECD Guidelines for the Testing of Chemicals; Organisation for Economic Co-operation and Development, 2000.

(14) Jolin, W. C.; Sullivan, J.; Vasudevan, D.; MacKay, A. A. Column Chromatography To Obtain Organic Cation Sorption Isotherms. Environ. Sci. Technol. 2016, 50, 8196-8204.

(15) Bi, E.; Schmidt, T. C.; Haderlein, S. B. Sorption of Heterocyclic Organic Compounds to Reference Soils: Column Studies for Process Identification. Environ. Sci. Technol. 2006, 40, 5962-5970.

(16) Droge, S.; Goss, K. U. Effect of sodium and calcium cations on the ion-exchange affinity of organic cations for soil organic matter. Environ. Sci. Technol. 2012, 46, 5894-5901.

(17) Metzelder, F.; Schmidt, T. C. Environmental Conditions Influencing Sorption of Inorganic Anions to Multiwalled Carbon Nanotubes Studied by Column Chromatography. Environ. Sci. Technol. 2017, 51, 4928-4935.

(18) Mader, B. T.; Uwe-Goss, K.; Eisenreich, S. J. Sorption of Nonionic, Hydrophobic Organic Chemicals to Mineral Surfaces. Environ. Sci. Technol. 1997, 31, 1079-1086.

(19) Bi, E.; Schmidt, T. C.; Haderlein, S. B. Environmental Factors Influencing Sorption of Heterocyclic Aromatic Compounds to Soil. Environ. Sci. Technol. 2007, 41, 3172-3178.

(20) Jolin, W. C.; Richard, A.; Vasudevan, D.; Gascon, J. A.; MacKay, A. A. Aluminosilicate Mineralogy and the Sorption of Organic Cations: Interplay between Electrostatic Barriers and Compound Structural Features. Environ. Sci. Technol. 2020, 54, $1623-1633$.

(21) Bronner, G.; Goss, K. U. Sorption of organic chemicals to soil organic matter: influence of soil variability and $\mathrm{pH}$ dependence. Environ. Sci. Technol. 2011, 45, 1307-1312.

(22) Bi, E.; Schmidt, T. C.; Haderlein, S. B. Practical issues relating to soil column chromatography for sorption parameter determination. Chemosphere 2010, 80, 787-793.

(23) Bi, E.; Schmidt, T. C.; Haderlein, S. B. Sorption of Heterocyclic Organic Compounds to Reference Soils: Column Studies for Process Identification. Environ. Sci. Technol. 2006, 40, 5962-5970.

(24) Valocchi, A. J. Validity of the Local Equilibrium Assumption for Modeling Sorbing Solute Transport Through Homogeneous Soil. Water Resour. Res. 1985, 21, 808-820.

(25) Percepta Platform (release 2016.2); Advanced Chemistry Development, Inc.: Toronto, Canada, 2016.

(26) Chemicalize; ChemAxon Ltd.: Budapest, Hungary, 2019. (https://chemicalize.com/).

(27) US EPA Estimation Programs Interface Suite for Microsoft Windows (4.11); United States Environmental Protection Agency: Washington DC, USA, 2017.

(28) Schönsee, C. D.; Bucheli, T. D. Experimental Determination of Octanol-Water Partition Coefficients of Selected Natural Toxins. J. Chem. Eng. Data 2020, 65, 1946-1953.

(29) Tolls, J. Sorption of Veterinary Pharmaceuticals in Soils: A Review. Environ. Sci. Technol. 2001, 35, 3397-3406.

(30) Zhi, Y.; Liu, J. Sorption and desorption of anionic, cationic and zwitterionic polyfluoroalkyl substances by soil organic matter and pyrogenic carbonaceous materials. Chem. Eng. J. 2018, 346, 682-691.

(31) Aristilde, L.; Sposito, G. Complexes of the antimicrobial ciprofloxacin with soil, peat, and aquatic humic substances. Environ. Toxicol. Chem. 2013, 32, 1467-1478.

(32) Grathwohl, P. Influence of Organic Matter from Soils and Sediments from Various Origins on the Sorption of Some Chlorinated
Aliphatic Hydrocarbons: Implications on Koc Correlations. Environ. Sci. Technol. 1990, 24, 1687-1693.

(33) Lyon, W. G. Swelling of Peats in Liquid Methyl, Tetramethylene and Propyl Sulfoxides and in liquid Propyl Sulfone. Environ. Toxicol. Chem. 1995, 14, 229-236.

(34) Schwarzenbach, R. P.; Gschwend, P. M.; Imboden, D. M. Environmental Organic Chemistry, 2nd ed.; Wiley-Interscience: Hoboken, New Jersey, US, 2003.

(35) MacKay, A. A.; Canterbury, B. Oxytetracycline Sorption to Organic Matter by Metal-Bridging. J. Environ. Qual. 2005, 34, 19641971.

(36) Rowley, M. C.; Grand, S.; Verrecchia, É. P. Calcium-mediated stabilisation of soil organic carbon. Biogeochemistry 2018, 137, 27-49.

(37) Kalinichev, A. G.; Kirkpatrick, R. J. Molecular dynamics simulation of cationic complexation with natural organic matter. Eur. J. Soil Sci. 2007, 58, 909-917.

(38) Droge, S. T.; Goss, K. U. Ion-exchange affinity of organic cations to natural organic matter: influence of amine type and nonionic interactions at two different pHs. Environ. Sci. Technol. 2013, 47, 798-806

(39) Fein, J. B., The effects of ternary surface complexes on the adsorption of metal cations and organic acids onto mineral surfaces. In Water-Rock Interactions, Ore Deposits, and Environmental Geochemistry: A Tribute to David A. Crerar; Hellmann, R., Wood, S. A., Eds.; The Geochemical Society, 2002.

(40) Vasudevan, D.; Stone, A. T. Adsorption of Catechols, 2Aminophenols, and 1,2-Phenylenediamines at the Metal (Hydr)Oxide/Water Interface: Effect of Ring Substituents on the Adsorption onto TiO2. Environ. Sci. Technol. 1996, 30, 1604-1613.

(41) Vasudevan, D.; Bruland, G. L.; Torrance, B. S.; Upchurch, V. G.; MacKay, A. A. pH-dependent ciprofloxacin sorption to soils: Interaction mechanisms and soil factors influencing sorption. Geoderma 2009, 151, 68-76.

(42) Aristilde, L.; Sposito, G. Binding of ciprofloxacin by humic substances: a molecular dynamics study. Environ. Toxicol. Chem. 2010, 29, 90-98.

(43) Wijnja, H.; Pignatello, J. J.; Malekani, K. Formation of $\pi-\pi$ Complexes between Phenanthrene and Model $\pi$-Acceptor Humic Subunits. J. Environ. Qual. 2004, 33, 265-275.

(44) Hunter, C. A.; Lawson, K. R.; Perkins, J.; Urch, C. J. Aromatic interactions. J. Chem. Soc., Perkin Trans. 2 2001, 651-669.

(45) Zhu, D.; Hyun, S.; Pignatello, J. J.; Lee, L. S. Evidence for $\pi-\pi$ Electron Donor-Acceptor Interactions between $\pi$-Donor Aromatic Compounds and $\pi$-Acceptor Sites in Soil Organic Matter through pH Effects on Sorption. Environ. Sci. Technol. 2004, 38, 4361-4368.

(46) Carrasquillo, A. J.; Bruland, G. L.; MacKay, A. A.; Vasudevan, D. Sorption of Ciprofloxacin and Oxytetracycline Zwitterions to Soils and Soil Minerals: Influence of Compound Structure. Environ. Sci. Technol. 2008, 42, 7634-7642.

(47) Zhu, W.-L.; Jiang, H.-L.; Puah, C. M.; Tan, X.-J.; Chen, K.-X.; Cao, Y.; Ji, R.-Y. Density functional theory (DFT) study on the interaction of ammonium (NH4+) and aromatic nitrogen heterocyclics. J. Chem. Soc., Perkin Trans. 2 1999, 2615-2622.

(48) Droge, S. T.; Goss, K. U. Development and evaluation of a new sorption model for organic cations in soil: contributions from organic matter and clay minerals. Environ. Sci. Technol. 2013, 47, 1423314241

(49) Jolin, W. C.; Goyetche, R.; Carter, K.; Medina, J.; Vasudevan, D.; MacKay, A. A. Predicting Organic Cation Sorption Coefficients: Accounting for Competition from Sorbed Inorganic Cations Using a Simple Probe Molecule. Environ. Sci. Technol. 2017, 51, 6193-6201.

(50) Schenzel, J.; Hungerbühler, K.; Bucheli, T. D. Mycotoxins in the environment: II. Occurrence and origin in Swiss river waters. Environ. Sci. Technol. 2012, 46, 13076-13084.

(51) Hoerger, C. C.; Wettstein, F. E.; Hungerbühler, K.; Bucheli, T. D. Occurrence and Origin of Estrogenic Isoflavones in Swiss River Waters. Environ. Sci. Technol. 2009, 43, 6151-6157.

(52) Clauson-Kaas, F.; Jensen, P. H.; Jacobsen, O. S.; Juhler, R. K.; Hansen, H. C. B. The naturally occurring carcinogen ptaquiloside is 
present in groundwater below bracken vegetation. Environ. Toxicol. Chem. 2014, 33, 1030-1034.

\section{- NOTE ADDED AFTER ASAP PUBLICATION}

Due to a production error, this paper was published ASAP on

March, 23, 2021, with an error in the article title. The corrected version was reposted on March 23, 2021. 